\title{
Catalpol protects mice against Lipopolysaccharide/D- galactosamine-induced acute liver injury through inhibiting inflammatory and oxidative response
}

\author{
Haogang Zhang ${ }^{1, *}$, Ruichun Jiaa ${ }^{2, *}$, Fujing Wang ${ }^{1, *}$, Gongcai Qiu ${ }^{1}$, Pengfei Qiao ${ }^{1}$, \\ Xunzheng $X \mathbf{u}^{1}$ and Dequan $\mathbf{W} \mathbf{u}^{1}$ \\ ${ }^{1}$ Department of General Surgery, The Second Affiliated Hospital of Harbin Medical University, Harbin, Heilongjiang 150086, \\ China \\ ${ }^{2}$ Department of Blood Transfusion, The Second Affiliated Hospital of Harbin Medical University, Harbin, Heilongjiang 150086, \\ China \\ *These authors contributed equally to this work
}

Correspondence to: Dequan Wu, email: wudequanlb@163.com

Keywords: lipopolysaccharide; D-galactosamine; acute liver injury; catalpol; TNF-a

Received: October 18, $2017 \quad$ Accepted: December 01, $2017 \quad$ Published: December 12, 2017

Copyright: Zhang et al. This is an open-access article distributed under the terms of the Creative Commons Attribution License 3.0 (CC BY 3.0), which permits unrestricted use, distribution, and reproduction in any medium, provided the original author and source are credited.

\begin{abstract}
The purpose of this study was to investigate the protective effect of catalpol on Lipopolysaccharide (LPS)/D-galactosamine (D-gal)-induced acute liver injury in mice. The mouse model was established by injection of LPS and D-gal. Catalpol $(2.5,5,10 \mathrm{mg} / \mathrm{kg})$ were pretreated intraperitoneally $1 \mathrm{~h}$ before LPS and D-gal. The survival rate, AST, ALT, MDA, MPO activity, hepatic tissue histology, TNF-a level, and NF-KB activation were assayed. The results revealed that catalpol dose-dependently elevated the survival rate. Furthermore, catalpol reduced the activities of AST, ALT, MDA, and MPO. The production of TNF-a was also inhibited by treatment of catalpol. In addition, catalpol inhibited LPS/D-gal-induced NF-KB activation. The expression of Nrf2 and HO-1 were up-regulated by treatment of catalpol. These results indicated that pretreatment with catalpol could attenuate LPS/D-gal-induced acute liver injury in mice and the underlying mechanism may due to the inhibition of NF-KB signaling pathway and the activation of Nrf2 signaling pathway.
\end{abstract}

\section{INTRODUCTION}

Fulminant hepatic failure was characterized by hepatic encephalopathy, coagulopathy and progressive multiorgan failure [1]. There are many causes of the disease, such as bacteria, viral hepatitis, alcohol and other hepatotoxic drugs. And the mortality of hepatic failure remains high. To conveniently study the pathogenesis of the disease, Lipopolysaccharide (LPS) in combination with D-galactosamine (D-gal) was used to induce an experimental liver injury in mice. Studies have shown that this model is similar to clinically fulminant hepatic failure [2, 3]. LPS, the important composition of endotoxin of Gram-negative bacteria, causes liver injury, and D-gal results in lipid peroxidation though triggering oxidative stress of hepatocytes $[4,5]$. Based on the pathogenesis we know, specific and effective therapies are urgently needed to control this disease.
Catalpol, an effective active ingredient extracted from Rehmannia glutinosa, has been known to have multiple pharmacological activities, such as antiinflammatory and anti-oxidative effects [6, 7]. Catalpol has been reported to protect against LPS-induced acute lung injury in mice [8]. Catalpol has been known to prevent D-galactose-induced mitochondrial dysfunction in mice [9]. Furthermore, catalpol was found to attenuate LPS-elicited rat microcirculation disorder by inhibiting inflammatory response [10]. In addition, a previous study showed that catalpol could attenuate ovalbumin-induced asthma in mice [11]. But few papers can be found about the effects of catalpol on fulminant hepatic failure induced by LPS and D-gal. Therefore, we aimed to investigate the potential role of catalpol on LPS and D-gal induced fulminant hepatic failure and to further illuminate its underlying mechanism. 


\section{RESULTS}

\section{Catalpol reduces the survival rate and attenuates hepatotoxicity against LPS/D-gal induced hepatic injury in mice}

Animals challenged by LPS/D-gal all died at 24 $\mathrm{h}$, which was improved by pretreatment of catalpol in a dose dependent manner (Figure 1). Serum ALT and AST activities had a significant increase at $6 \mathrm{~h}$ after LPS/D-gal administration. However, the increase was prevented by pretreatment of catalpol (Figure 2).

\section{Catalpol ameliorates the changes of hepatic tissue challenged by LPS/D-gal in mice}

LPS/D-gal challenge caused a series of pathologic changes of liver, such as severe hemorrhagic necrosis, destruction of hepatic architecture, massive infiltration of inflammatory cells, while these changes were relatively slight with the pretreatment of catalpol (Figure 3).

\section{Catalpol decreases MDA production and MPO activity in LPS/D-gal induced mice}

It is known that MPO is a marker of tissue neutrophil infiltration. As shown in Figure 4, a significant increase of MPO activity was observed in mice after LPS/ D-gal challenge compared with mice of the control group, whereas pretreatment with catalpol dose-dependently decreased MPO activity induced by LPS/D-gal. The effects of catalpol on MDA production were measured. As shown in Figure 4, a significant increase of MDA level was observed in mice after LPS/D-gal challenge compared with mice of the control group, whereas pretreatment with catalpol dose-dependently decreased MDA level induced by LPS/D-gal.

\section{Catalpol reduces TNF- $\alpha$ production induced by LPS/D-gal in mice}

TNF- $\alpha$ is a pivotal mediator in LPS/D-gal induced liver injury. In the present study, LPS/D-gal challenge significantly increased the levels of serum and hepatic TNF- $\alpha$ in mice. However, a decrease was observed in mice treated with catalpol in a dose-dependent manner (Figure 5).

\section{Catalpol inhibits NF-кB activation in LPS/D-gal induced mice}

NF- $\kappa \mathrm{B}$ plays a key role in LPS/D-gal induced liver injury, which is a crucial transcriptional factor in the regulation of TNF- $\alpha$ transcription [12]. After LPS/D-

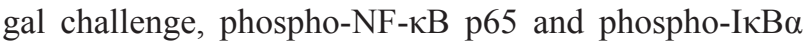
proteins were markedly increased in mice compared to that in the control group. Pretreatment with catalpol dosedependently decreased the phosphorylation of NF- $\mathrm{KB}$ p 65 and IKB $\alpha$ (Figure 6).

\section{Effects of catalpol on $\mathrm{Nrf} 2$ and HO-1 expression in LPS/D-gal induced mice}

Nrf2 signaling pathway plays an important role in the regulation of oxidative response. In the present study, we detected the effects of catalpol on Nrf2 signaling pathway to assess the anti-oxidative mechanism of catalpol. After LPS/D-gal challenge, the expression of Nrf2 and HO-1 proteins were increased in mice compared to that in the control group. Pretreatment with catalpol dose-dependently increased the expression of Nrf2 and HO-1 (Figure 7).

\section{DISCUSSION}

Galactosamine is a hexosamine derived from galactose with the molecular formula $\mathrm{C}_{6} \mathrm{H}_{13} \mathrm{NO}_{5}$. D-GalN is a specific hepatotoxic agent metabolized exclusively in hepatocytes, which reduces intracellular pool of uracil nucleotides, thus inhibiting the synthesis of RNA and proteins. LPS, a major constituent of Gram-negative bacterial membrane, specifically activates Toll-like receptor 4 , leading to the production of cytokines which in turn regulate inflammatory and innate and subsequent adaptive immune responses. It is reported that LPS in combination with D-gal highly sensitizes animals to develop lethal liver injury showing biochemical and metabolic changes similar to fulminant hepatic failure [13]. In the present study, we aimed to investigate the effects of catalpol on fulminant hepatic failure based on this animal model induced by LPS/D-gal. Pretreatment with catalpol attenuated LPS/D-gal induced liver injury, as indicated by the reduction of lethality, ALT/AST activities, MPO activity and tissue pathological injury.

TNF- $\alpha$ is known to be a pleiotropic cytokine that contributes to the triggering of an inflammatory cascade involving the induction of cytokines including IL-1, IL-6, IFN- $\gamma$, nitric oxide and cell adhesion molecules [14]. At the later stages of liver injury, TNF- $\alpha$-induces neutrophil transmigration, which plays a crucial role in hepatocyte necrosis [15]. Furthermore, the key role of TNF- $\alpha$ in LPS/D-gal induced hepatotoxicity has been confirmed by experiments with TNF- $\alpha$ knockout or TNF-receptor p55 knockout mice $[16,17]$. Our results showed that serum and hepatic TNF- $\alpha$ levels had a markedly increase in LPS/D-gal induced mice. However, pretreatment with catalpol dose-dependently decreased the levels. Therefore, catalpol may protect liver injury through inhibiting TNF- $\alpha$ production in LPS/D-gal induced mice. MDA, a biomarker of oxidative stress, was measured to assess the antioxidative effects of catalpol. The results suggested that catalpol inhibited LPS/D-gal-induced oxidative response 


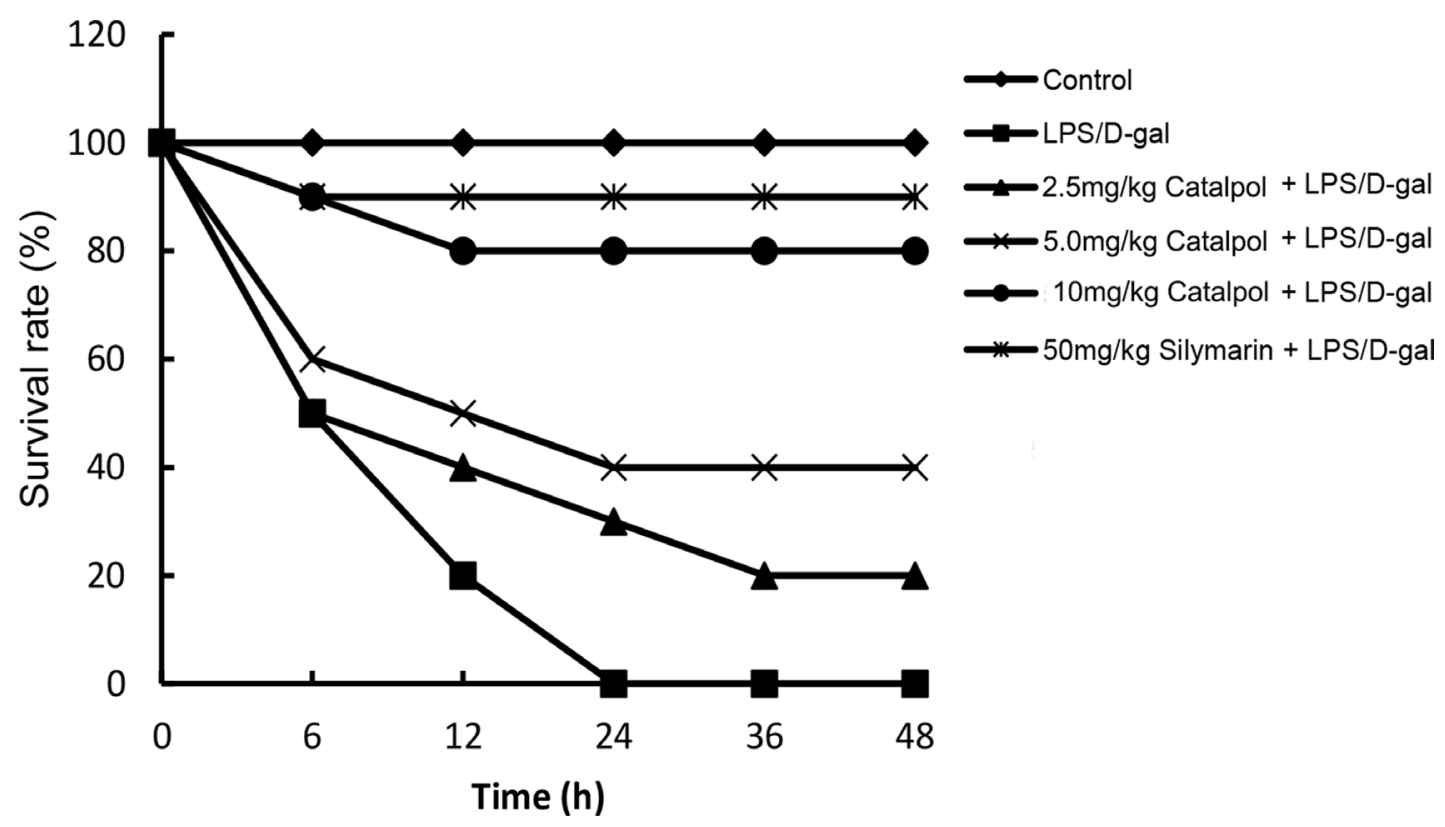

Figure 1: Effects of catalpol on LPS/D-gal induced mortality in mice $(\boldsymbol{n}=\mathbf{1 2})$. Balb/c mice were pretreated intraperitoneally with catalpol $(2.5,5,10 \mathrm{mg} / \mathrm{kg})$ or PBS injection $1 \mathrm{~h}$ before LPS/D-gal administration.
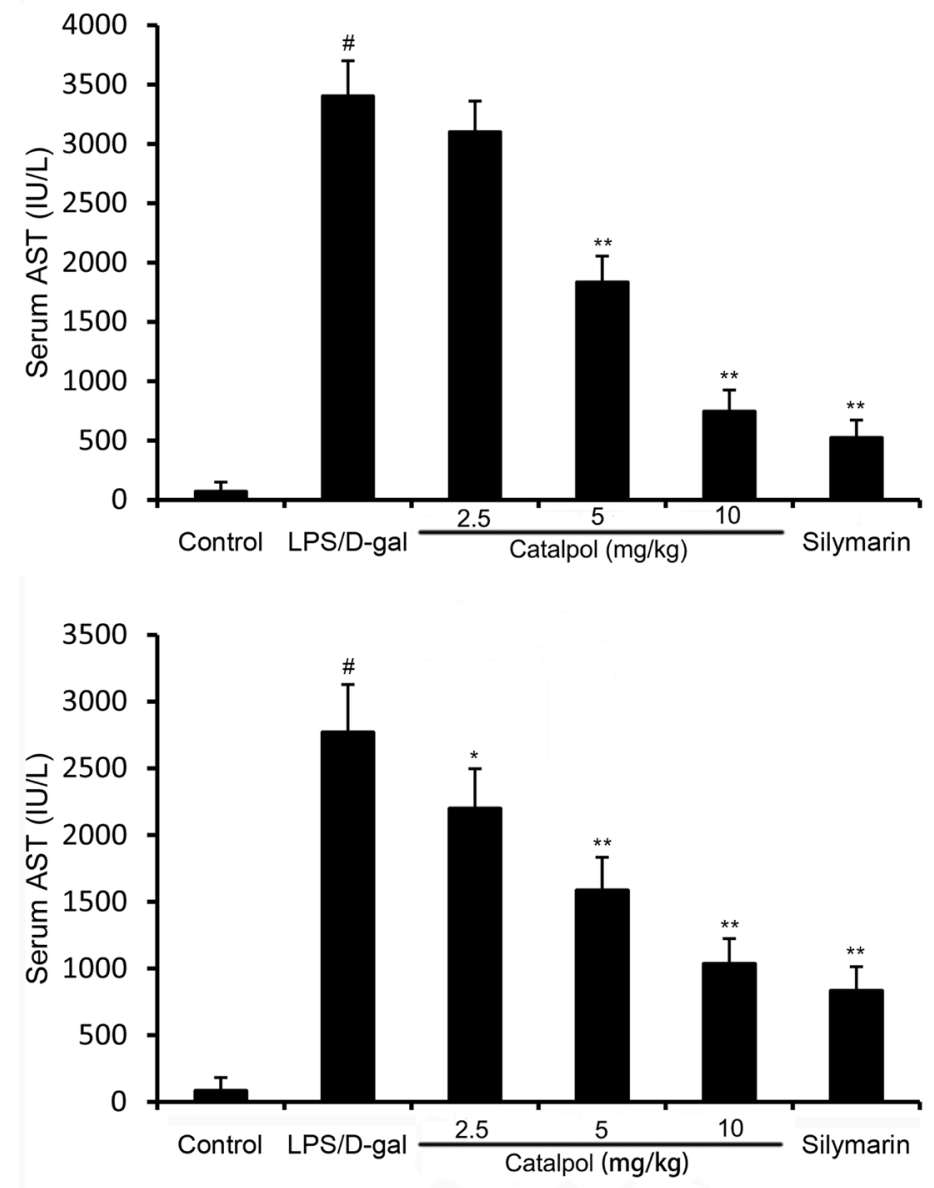

Figure 2: Effects of catalpol on ALT and AST activities in mice after LPS/D-gal treatment. Balb/c mice were pretreated intraperitoneally with catalpol $(2.5,5,10 \mathrm{mg} / \mathrm{kg})$ or PBS injection $1 \mathrm{~h}$ before LPS/D-gal administration. The values presented are the mean \pm SEM. $p^{\#}<0.01$ vs. control group, $p^{*}<0.05, p^{* *}<0.01$ vs. LPS/D-gal group. 


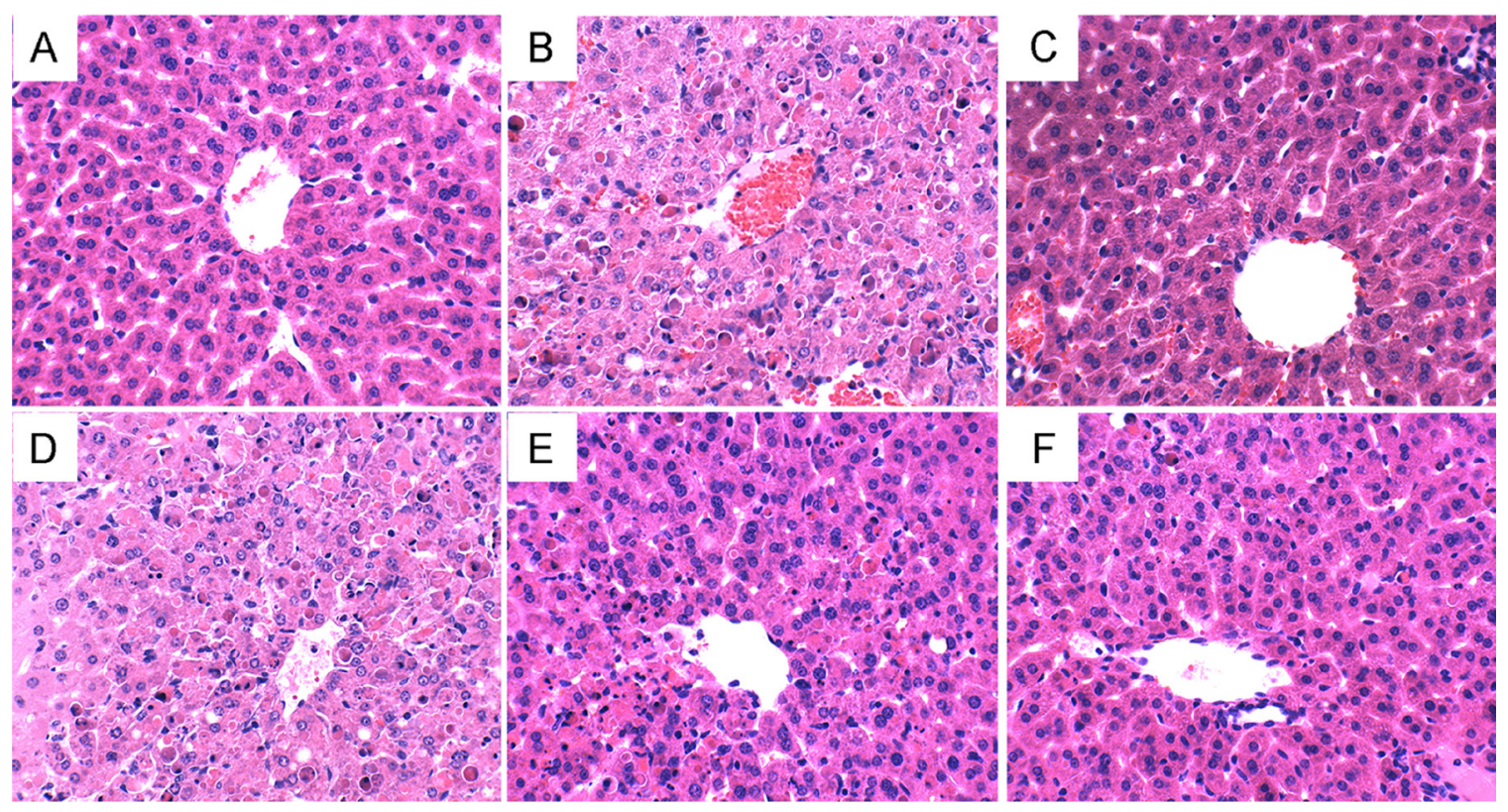

Figure 3: Histopathologic sections of thelivers $(\mathrm{H} \& \mathrm{E}, \times \mathbf{4 0 0})$. (A) Control group treated with PBS. (B) Group treated with LPS/Dgal. (C) Group treated with $50 \mathrm{mg} / \mathrm{kg}$ silymarin. (D) Group pretreated with $2.5 \mathrm{mg} / \mathrm{kg}$ catalpol $1 \mathrm{~h}$ before LPS/D-gal administration. (E) Group pretreated with $5 \mathrm{mg} / \mathrm{kg}$ catalpol $1 \mathrm{~h}$ before LPS/D-gal administration. (F) Group pretreated with $10 \mathrm{mg} / \mathrm{kg}$ catalpol $1 \mathrm{~h} \mathrm{before}$ LPS/D-gal administration.
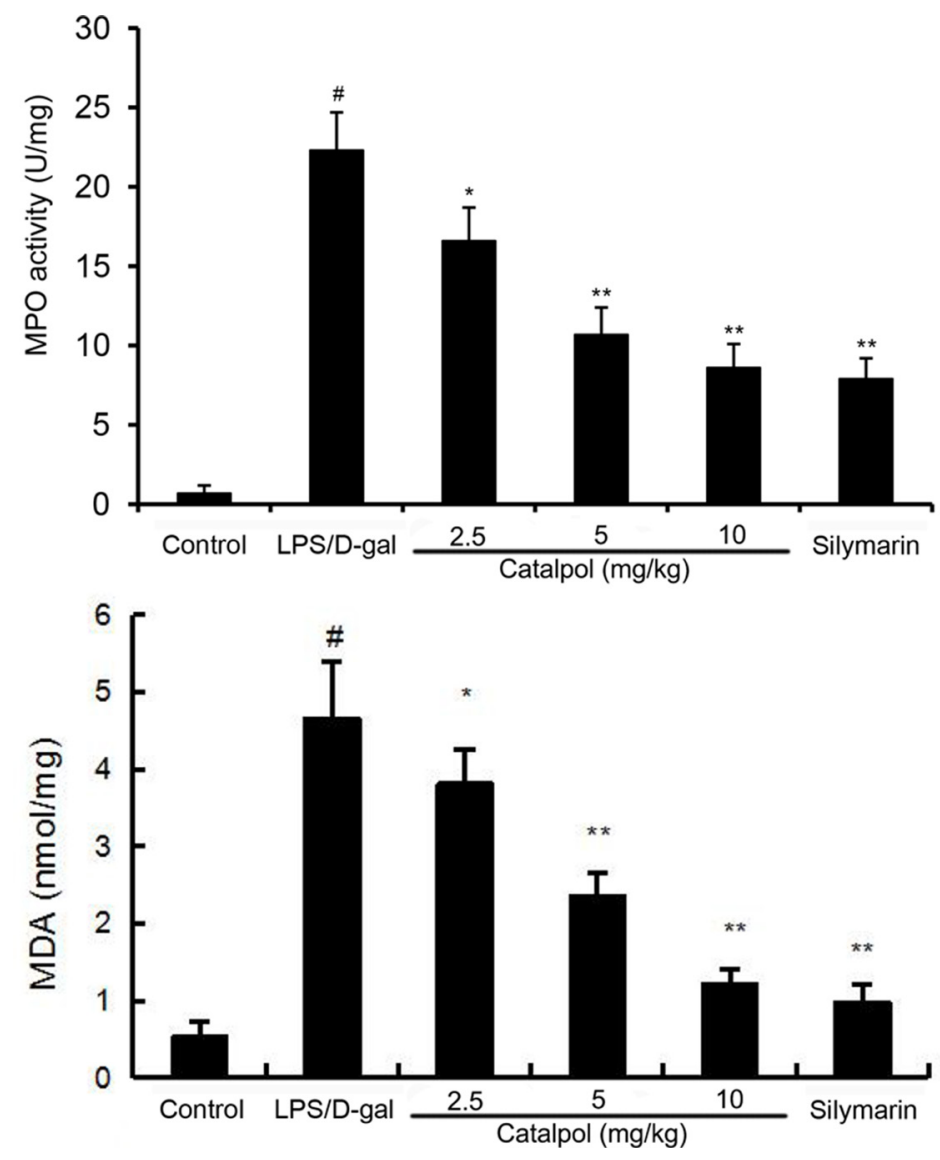

Figure 4: Effects of catalpol on MDA level and MPO activity in LPS/D-gal induced mice. Mice were given an intraperitoneal injection of catalpol $(2.5,5,10 \mathrm{mg} / \mathrm{kg})$ or PBS $1 \mathrm{~h}$ before LPS administrationrespectively. The values presented are the mean \pm SEM. $p^{\#}<$ 0.01 vs. control group, $p^{*}<0.05, p^{* *}<0.01$ vs. LPS group. 
in mice. These results indicated that catalpol protected against LPS/D-gal-induced fulminant hepatic failure by suppressing inflammatory and oxidative responses.

$\mathrm{NF}-\mathrm{\kappa B}$ is implicated in the regulation of inflammatory and immune responses which plays an important role in serious diseases $[18,19]$. In resting cells, $\mathrm{NF}-\kappa \mathrm{B}$ family members are sequestered in the cytoplasm, for they are bound to their inhibitors which belong to the I $\mathrm{I} B$ family. Upon cell activation, I $\mathrm{B}$ proteins are phosphorylated and degraded by the proteasome. Subsequently, NF- $\kappa \mathrm{B}$ could enter the nucleus and bind to the DNA, resulting in promoting transcription [20]. It is known that TNF- $\alpha$ transcription stimulated by LPS is regulated by $\mathrm{NF}-\kappa \mathrm{B}$ [21]. Moreover, studies have shown that NF- $\kappa \mathrm{B}$ played a vital role in LPS/D-gal liver injury $[22,23]$. To further explore the mechanism of catalpol on liver injury in LPS/D-gal induced mice, NF- $\kappa \mathrm{B}$ was assayed by western blot. The results revealed that NF- $\kappa B$ activation was dose-dependently inhibited by pretreatment with catalpol in LPS/D-gal induced mice. Hence, we speculated that the reduction of TNF- $\alpha$ production by catalpol may be associated with the inhibition of NF- $\mathrm{NB}$ activation. Nrf2 signaling pathway was involved in the development of oxidative response [24]. Activation of Nrf2 has been reported to protect against liver injury [25, $26]$. In the present study, our results showed that catalpol could increase the expression of $\mathrm{Nrf} 2$ and HO-1. The results suggested that catalpol inhibited oxidative stress by activating Nrf2 signaling pathway.

In conclusion, the protective effect of catalpol against LPS/D-gal induced liver injury in mice appeared to be closely related to the inhibition of $\mathrm{NF}-\kappa \mathrm{B}$ activation
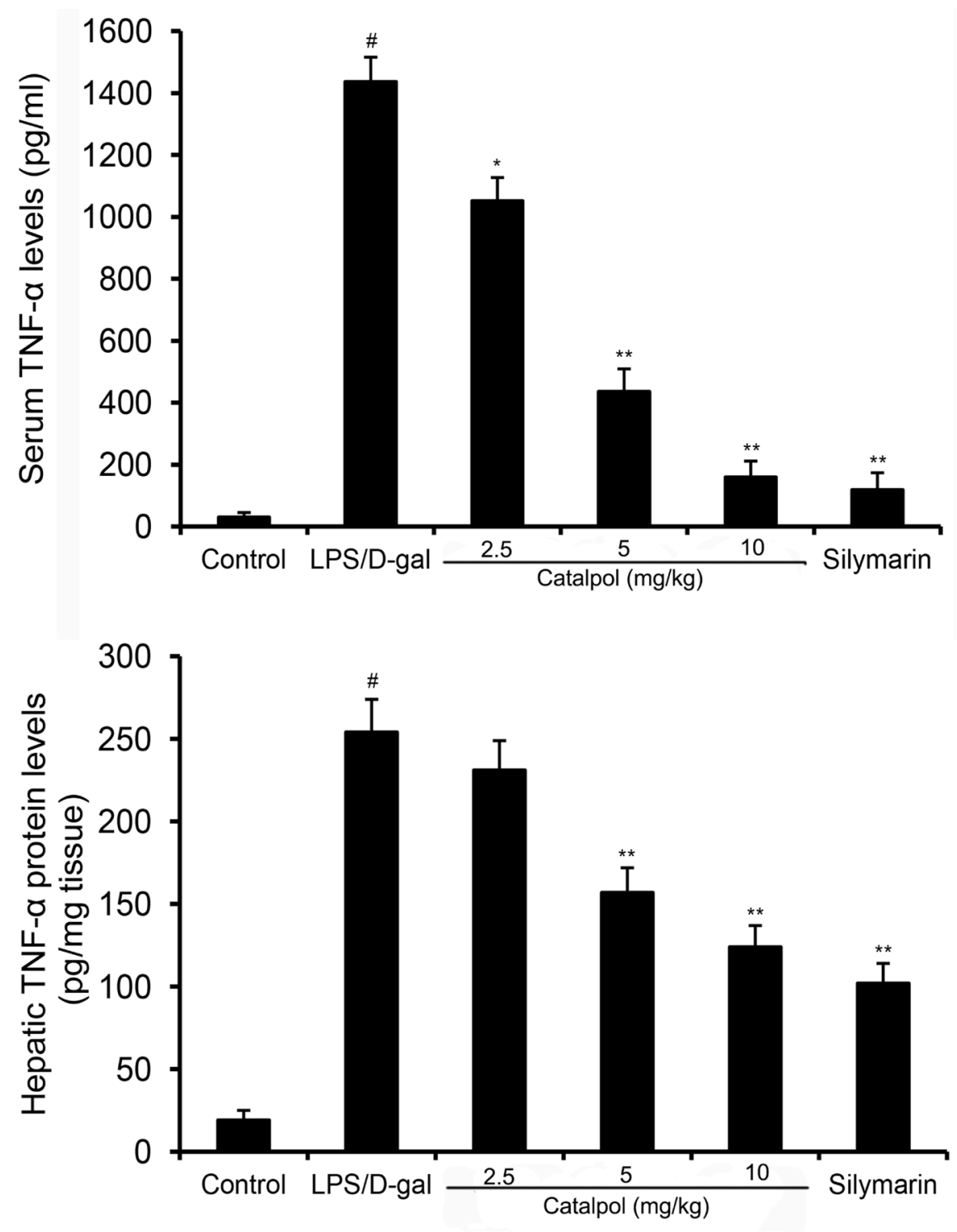

Figure 5: Effects of catalpol on serum and hepatic TNF- $\alpha$ levels in LPS/D-gal induced mice. Mice were given an intraperitoneal injection of catalpol $(2.5,5,10 \mathrm{mg} / \mathrm{kg})$ or PBS $1 \mathrm{~h}$ before LPS administration respectively. The values presented are the mean \pm SEM. $p^{\#}<0.01$ vs. control group, $p^{*}<0.05, p^{* *}<0.01$ vs. LPS group. 
and activation of Nrf2. To acquire a better understanding of the effect of catalpol on LPS/D-gal induced liver injury, further and more work will be required.

\section{MATERIALS AND METHODS}

\section{Reagents}

Catalpol (purity $\geq 98 \%$ ) was purchased from Sigma (St. Louis, MO, USA) and prepared with dimethyl sulfoxide (DMSO). LPS (Escherichia coli, 0111:B4) and D-gal were obtained from Sigma (St. Louis, MO, USA). Alanine aminotransferase (ALT), aspartate aminotransferase (AST) assay kits were purchased from Nanjing Jiancheng Bioengineering Institute (Nanjing, China). The myeloperoxidase (MPO) kit was provided by the Jiancheng Bioengineering Institute of Nanjing (Nanjing, Jiangsu, China). Mouse TNF- $\alpha$ enzyme-linked immunosorbent assay (ELISA) kit was purchased from BioLegend (CA, USA). Rabbit anti-mouse phospho-NF$\kappa \mathrm{B}$ p65, anti-mouse $\mathrm{I} \kappa \mathrm{B} \alpha$, mouse mAbphospho-I $\kappa \mathrm{B} \alpha$, anti-mouse Nrf2, anti-mouse HO-1, and rabbit anti-mouse
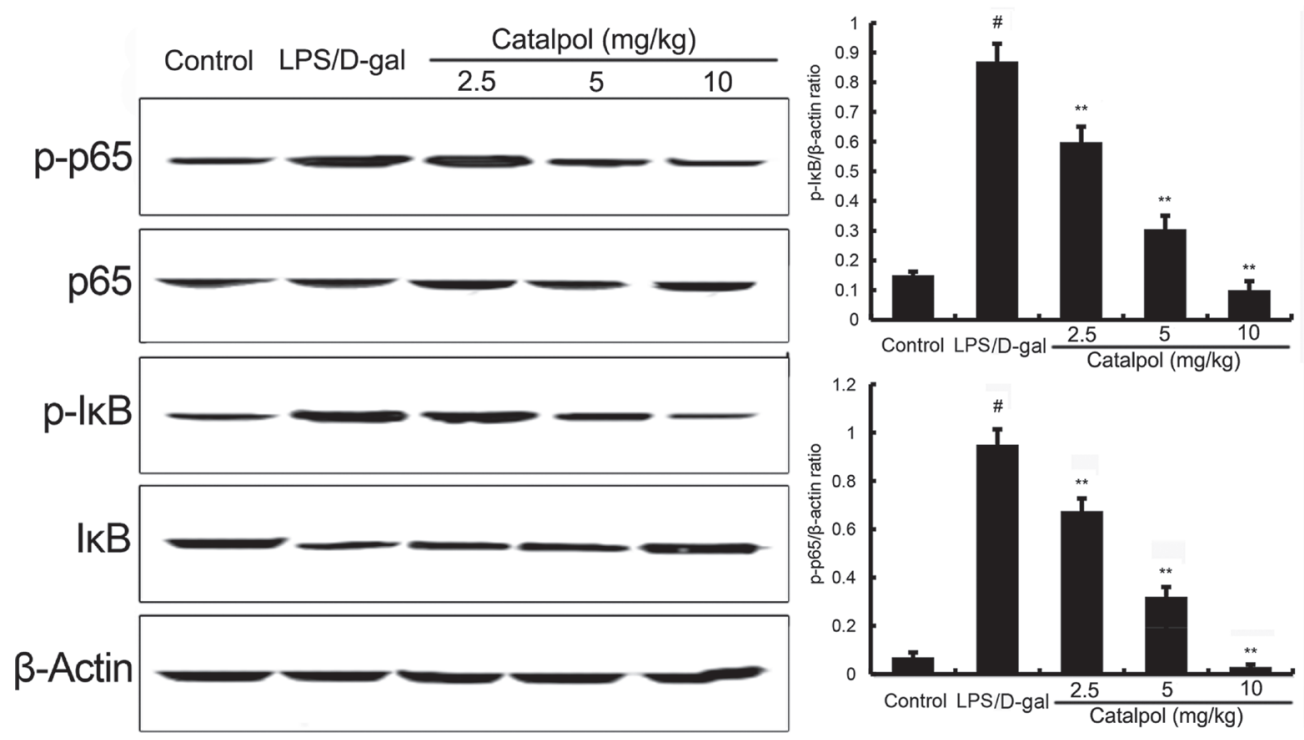

Figure 6: Effects of catalpol on LPS/D-gal induced NF-кB activation in mice. Balb/c mice were pretreated intraperitoneally with catalpol $(2.5,5,10 \mathrm{mg} / \mathrm{kg})$ or PBS injection $1 \mathrm{~h}$ before LPS/D-gal administration. $\beta$-Actin was used as a control. The values presented are the mean \pm SEM. $p^{\#}<0.01$ vs. control group, $p^{*}<0.05, p^{* *}<0.01$ vs. LPS group.
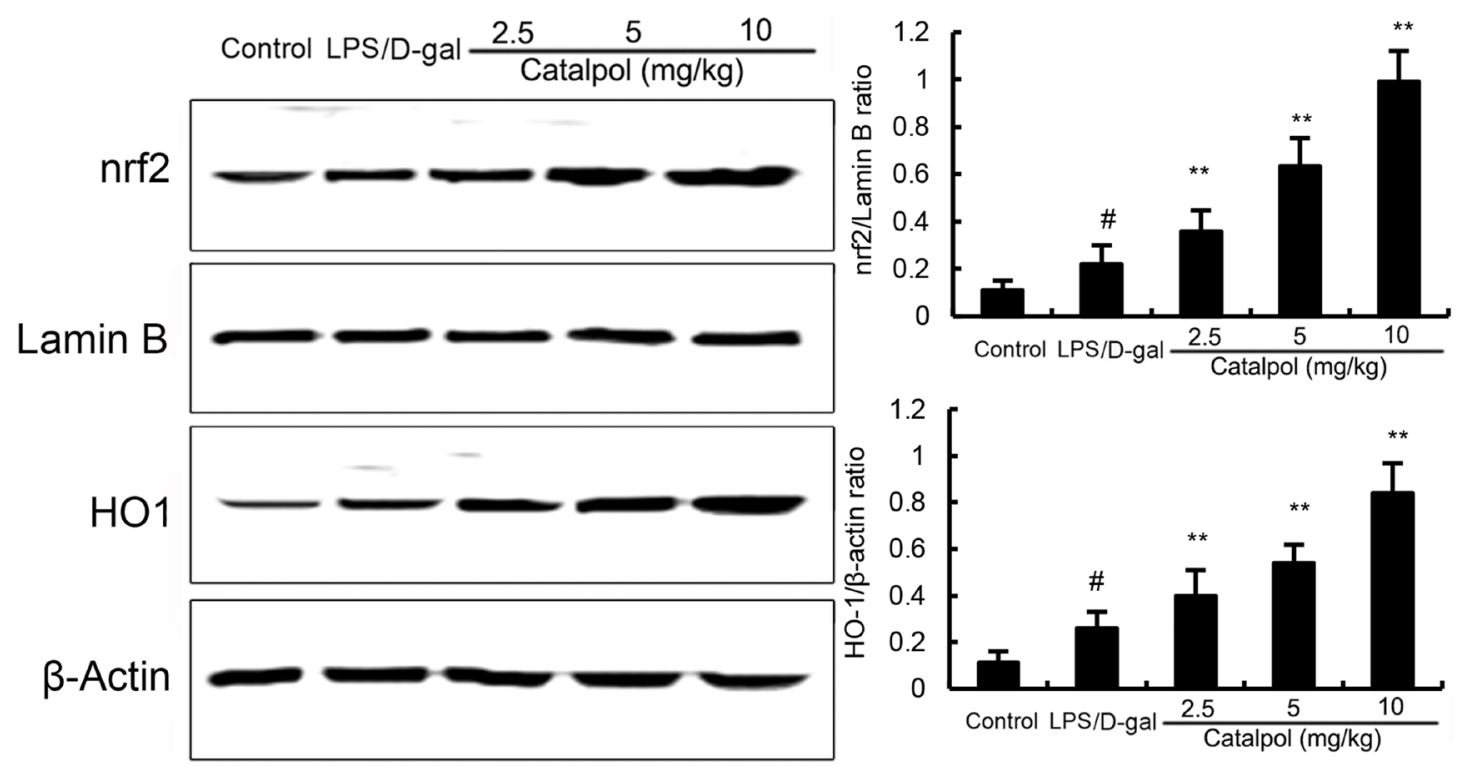

Figure 7: Effects of catalpol on Nrf2 and HO-1 expresssion in mice. Balb/c mice were pretreated intraperitoneally with catalpol $(2.5,5,10 \mathrm{mg} / \mathrm{kg})$ or PBS injection $1 \mathrm{~h}$ before LPS/D-gal administration. $\beta$-Actin was used as a control. The values presented are the mean \pm SEM. $p^{\#}<0.01$ vs. control group, $p^{*}<0.05, p^{* *}<0.01$ vs. LPS group. 
beta-actin antibody were purchased from Cell Signaling Technology Inc. (Beverly, MA). HRP-conjugated goat anti-rabbit and goat-mouse antibodies were provided by GE Healthcare (Buckinghamshire, UK).

\section{Animals}

Specific pathogen-free male $\mathrm{BALB} / \mathrm{c}$ mice $(6-8$ weeks old; $18-20 \mathrm{~g}$ ) were purchased from the Center of Experimental Animals of Harbin Medical University (Harbin, China). The mice were kept in controlled conditions $\left(23^{\circ} \mathrm{C}, 55 \%\right.$ humidity and $12 \mathrm{~h}$ day/night cycle). Prior to experiments, all mice were accustomed to the new environment for at least 1 week, and supplied with standard rodent feed and tap water ad libitum. The animal study protocol was approved by the Harbin Medical University Animal Care and Use Committee and all animal experiments were performed in accordance with the National Institutes of Health guide for the Care and Use of Laboratory Animals.

\section{Experimental design}

Seventy-two mice were divided into six groups and each group contained twelve mice. Mice were administered with catalpol $(2.5,5,10 \mathrm{mg} / \mathrm{kg})$ dissolved in $250 \mu \mathrm{l}$ phosphate-buffered saline (PBS) once daily for three days prior to challenge experimentation. The dose of catalpol used in this study was based on our preliminary experiment and previous study [8]. The mice of control group were given an equal volume of PBS. Mice given an isometric silymarin $(50 \mathrm{mg} / \mathrm{kg}$ ) were used as positive control. Fulminant hepatic failure in mice were induced by the intraperitoneal injection of LPS $(50 \mu \mathrm{g} / \mathrm{kg})$ and D-gal $(800 \mathrm{mg} / \mathrm{kg})$ combination dissolved in PBS. The survival rate of the mice was evaluated within $48 \mathrm{~h}$ after LPS/D-gal injection.

\section{Analysis of liver enzymes}

Blood was collected at $6 \mathrm{~h}$ after LPS/D-gal injection. Serum ALT and AST levels were measured by using corresponding assay kits according to the manufacturer's instructions.

\section{Histological evaluation}

Liver tissue was collected at $6 \mathrm{~h}$ after LPS/D-gal injection and fixed in 10\% neutral-buffered formalin. Then the samples were sliced into $5 \mu \mathrm{m}$ sections and stained with hematoxylin-eosin. Finally, the pathologic changes were observed under a light microscope.

\section{MPO assay}

Liver samples were homogenized in PBS and centrifuged at $10000 \times \mathrm{g}$ for $10 \mathrm{~min}$. The supernatant was collected for further determinations and the resultant pellets were removed. MPO activity in liver tissues was assayed following the manufacturer's protocol of MPO kit.

\section{Measurement of TNF- $\alpha$ level}

Serum and hepatic tissues were collected for the detection of TNF- $\alpha$. The TNF- $\alpha$ level in serum and hepatic tissues was measured by mouse TNF- $\alpha$ ELISA kit according to the manufacturer's protocol.

\section{Western blotting}

The liver tissue was homogenated with a lysis buffer, and then centrifuged at $3000 \times \mathrm{g}$ for $10 \mathrm{~min}$ at $4{ }^{\circ} \mathrm{C}$. The supernatant was collected and the total protein concentration was measured using a BCA protein assay kit. For western blotting, the detail procedures were similar to previous study [27]. The protein levels of Nrf2, HO-1, p65, phosphorylated-p65, IкB $\alpha$, phosphorylatedI $\kappa \mathrm{B} \alpha$ were assayed by western blotting.

\section{Statistical analysis}

Data were expressed as mean \pm SEM. Differences between the mean values of normally distributed data were assessed by one-way ANOVA (Dunnett's $t$ test) and the two-tailed Student's $t$ test. Statistical significance was set at $p<0.05$.

\section{CONFLICTS OF INTEREST}

The author declares that there are no conflicts of interest.

\section{FUNDING}

This study was supported by grants from the Scientific Research Fund of Heilongjiang Provincial Education Department (NO. 12541368) and the scientific research of the health and Family Planning Commission of Heilongjiang province of China (NO. 2013045).

\section{REFERENCES}

1. Trey C, Davidson CS. The management of fulminant hepatic failure. Prog Liver Dis. 1970; 3:282.

2. Wang HP, Li Y. Protective effect of bicyclol on acute hepatic failure induced by lipopolysaccharide and D-galactosamine in mice. Eur J Pharmacol. 2006; 534:194-201.

3. Lu J, Chen YP, Wan R, Guo CY, Wang XP. Protective Effects of Ulinastatin on Acute Liver Failure Induced by Lipopolysaccharide/D-Galactosamine. Dig Dis Sci. 2012; 57:399-404.

4. Morikawa A, Kato Y, Sugiyama T, Koide N, Chakravortty D, Yoshida T, Yokochi T. Role of nitric 
oxide in lipopolysaccharide-induced hepatic injury in D-galactosamine-sensitized mice as an experimental endotoxic shock model. Infect Immun. 1999; 67:1018-1024.

5. Malhi H, Gores GJ. Cellular and molecular mechanisms of liver injury. Gastroenterology. 2008; 134:1641-1654.

6. Zhou J, Xu G, Ma S, Li F, Yuan M, Xu H, Huang K. Catalpol ameliorates high-fat diet-induced insulin resistance and adipose tissue inflammation by suppressing the JNK and NF-kappaB pathways. Biochem Biophys Res Commun. 2015; 467:853-858.

7. Tian YY, Jiang B, An LJ, Bao YM. Neuroprotective effect of catalpol against $\mathrm{MPP}(+)$-induced oxidative stress in mesencephalic neurons. Eur J Pharmacol. 2007; 568:142-148.

8. Fu K, Piao T, Wang M, Zhang J, Jiang J, Wang X, Liu H. Protective effect of catalpol on lipopolysaccharide-induced acute lung injury in mice. Int Immunopharmacol. 2014; 23:400-406.

9. Zhang X, Liu W, Niu X, An L. Systemic administration of catalpol prevents D-galactose induced mitochondrial dysfunction in mice. Neurosci Lett. 2010; 473:224-228.

10. Zhang YP, Pan CS, Yan L, Liu YY, Hu BH, Chang X, Li Q, Huang DD, Sun HY, Fu G, Sun K, Fan JY, Han JY. Catalpol restores LPS-elicited rat microcirculation disorder by regulation of a network of signaling involving inhibition of TLR-4 and SRC. Am J Physiol Gastrointest Liver Physiol. 2016; 311:G1091-G1104.

11. Chen Y, Zhang Y, Xu M, Luan J, Piao S, Chi S, Wang H. Catalpol alleviates ovalbumin-induced asthma in mice: Reduced eosinophil infiltration in the lung. Int Immunopharmacol. 2017; 43:140-146.

12. Wu Z, Kong $\mathrm{X}$, Zhang $\mathrm{T}$, Ye J, Fang $\mathrm{Z}$, Yang $\mathrm{X}$. Pseudoephedrine/ephedrine shows potent anti-inflammatory activity against TNF- $\alpha$-mediated acute liver failure induced by lipopolysaccharide/d-galactosamine. Eur J Pharmacol. 2014; 724:112-121.

13. Freudenberg MA, Galanos C. Induction of tolerance to lipopolysaccharide (LPS)-D-galactosamine lethality by pretreatment with LPS is mediated by macrophages. Infect Immun. 1988; 56:1352-1357.

14. Tiegs G, Wolter M, Wendel A. Tumor necrosis factor is a terminal mediator in galactosamine/endotoxin-induced hepatitis in mice. Biochem Pharmacol. 1989; 38:627-631.

15. Josephs MD, Bahjat FR, Fukuzuka K, Ksontini R, Solorzano CC, Edwards CK 3rd, Tannahill CL, MacKay SL, Copeland EM 3rd, Moldawer LL. Lipopolysaccharide and D-galactosamine-induced hepatic injury is mediated by TNF- $\alpha$ and not by Fas ligand. Am J Physiol. 2000; 278:R1196-R1201.
16. Nowak M, Gaines GC, Rosenberg J, Minter R, Bahjat F, Rectenwald J, MacKay SL, Edwards CK 3rd, Moldawer LL. LPS-induced liver injury ind-galactosamine-sensitized mice requires secreted TNF- $\alpha$ and the TNF-p55 receptor. Am J Physiol. 2000; 278:R1202-R1209.

17. Greeneltch KM, Haudenschild CC, Keegan AD, Shi Y. The opioid antagonist naltrexone blocks acute endotoxic shock by inhibiting tumor necrosis factor- $\alpha$ production. Brain Behav Immun. 2004; 18:476-484.

18. Kumar A, Takada Y, Boriek AM, Aggarwal BB. Nuclear factor-kappaB: its role in health and disease. J Mol Med. 2004; 82:434-448.

19. Wang J, Guo C, Wei Z, He X, Kou J, Zhou E, Yang Z, Fu Y. Morin suppresses inflammatory cytokine expression by downregulation of nuclear factor-kappaB and mitogenactivated protein kinase (MAPK) signaling pathways in lipopolysaccharide-stimulated primary bovine mammary epithelial cells. J Dairy Sci. 2016; 99:3016-3022.

20. Natoli G. NF-kappa B and chromatin: ten years on the path from basic mechanisms to candidate drugs. Immunol Rev. 2012; 246:183-192.

21. Diehl AM. Cytokine regulation of liver injury and repair. Immunol Rev. 2000; 174:160-171.

22. Gong X, Luo F, Zhang L, Li HZ, Wu MJ, Li XH, Wang $\mathrm{B}, \mathrm{Hu} \mathrm{N}$, Wang $\mathrm{CD}$, Yang JQ. Tetrandrine attenuates lipopolysaccharide-induced fulminant hepatic failure in D-galactosamine-sensitized mice. Int Immunopharmacol. 2010; 10:357-363.

23. Pan Q, Liu Y, Zheng J, Lu X, Wu S, Zhu P, Fu N. Protective effect of chloral hydrate against lipopolysaccharide/Dgalactosamine-induced acute lethal liver injury and zymosan-induced peritonitis in mice. Int Immunopharmacol. 2010; 10:967-977.

24. Nguyen T, Nioi P, Pickett CB. The Nrf2-antioxidant response element signaling pathway and its activation by oxidative stress. J Biol Chem. 2009; 284:13291-13295.

25. Xu W, Hellerbrand C, Kohler UA, Bugnon P, Kan YW, Werner S, Beyer TA. The Nrf2 transcription factor protects from toxin-induced liver injury and fibrosis. Lab Invest. 2008; 88:1068-1078.

26. Wu KC, Liu JJ, Klaassen CD. Nrf2 activation prevents cadmium-induced acute liver injury. Toxicol App Pharmacol. 2012; 263:14-20.

27. Zhou E, Li Y, Wei Z, Fu Y, Lei H, Zhang N, Yang Z, Xie G. Schisantherin A protects lipopolysaccharide-induced acute respiratory distress syndrome in mice through inhibiting NF- $\mathrm{\kappa B}$ and MAPKs signaling pathways. Int Immunopharmacol. 2014; 22:133-140. 